\title{
Adrenal Activity during Repeated Long-Access Cocaine Self-Administration is Required for Later CRF-Induced and CRF-Dependent Stressor-Induced Reinstatement in Rats
}

\author{
Evan N Graf', Michael A Hoks', Jean Baumgardner', Jose Sierra', Oliver Vranjkovic', Colin Bohr', \\ David A Baker' and John R Mantsch*,' \\ 'Department of Biomedical Sciences, Marquette University, Milwaukee, WI, USA
}

\begin{abstract}
Understanding the neurobiological processes that contribute to the establishment and expression of stress-induced regulation of cocaine use in addicted individuals is important for the development of new and better treatment approaches. It has been previously shown that rats self-administering cocaine under long-access conditions (6h daily) display heightened susceptibility to the reinstatement of extinguished cocaine seeking by a stressor, electric footshock, or i.c.v. administration of the stressor-responsive neuropeptide, corticotropin-releasing factor (CRF). This study tested the hypothesis that adrenal responsiveness during earlier long-access cocaine selfadministration (SA) is necessary for the establishment of later CRF-dependent stress-induced reinstatement. Reinstatement by footshock, but not a cocaine challenge $(10 \mathrm{mg} / \mathrm{kg}$, i.p.) following long-access SA, was blocked by i.c.v. administration of the CRF receptor antagonist, $\alpha$-helical $\mathrm{CRF}_{9-4 \mathrm{I}}(\mathrm{IO} \mu \mathrm{g})$. Elimination of SA-induced adrenal responses through surgical adrenalectomy and diurnal corticosterone replacement $(A D X / C)$ before 14 days of SA under long-access conditions had minimal impact on cocaine SA, but blocked later footshock-induced reinstatement. By contrast, ADX/C after SA, but before extinction and reinstatement testing, failed to reduce footshock-induced reinstatement. Likewise, ADX/C before 14 days long-access SA prevented later reinstatement by i.c.v. CRF ( 0.5 or $1.0 \mu \mathrm{g}$ ). However, significant CRF-induced reinstatement was observed when rats underwent ADX/C following SA, but before extinction and reinstatement testing, although a modest but statistically nonsignificant reduction in sensitivity to CRF's reinstating effects was observed. Taken together, these findings suggest that adrenal-dependent neuroadaptations in CRF responsiveness underlie the increased susceptibility to stress-induced relapse that emerges with repeated cocaine use.

Neuropsychopharmacology (20 I I) 36, I444-1454; doi: I0.1038/npp.20 I I.28; published online I6 March 20I I
\end{abstract}

Keywords: relapse; stress; CRF; CRH; glucocorticoid; cocaine

\section{INTRODUCTION}

The unpredictable relapse of drug use that emerges even after extended periods of drug abstinence is a major obstacle to the effective management of cocaine addiction. This chronically relapsing nature of addiction is likely attributable to neuroplasticity that emerges in an intakedependent manner as a consequence of repeated drug use and can be studied in rats using the reinstatement approach. A large body of evidence suggests that stressful life events can precipitate or promote drug relapse. Reports that stressors can provoke craving in human cocaine addicts (Sinha et al, 1999, 2000) are paralleled by findings

*Correspondence: Dr JR Mantsch, Department of Biomedical Sciences, Marquette University, Schroeder Health Complex, Box I88I, Milwaukee, WI 5320I-I88I, USA, Tel: + | 4142882036 ,

Fax: + 414288 6564, E-mail: john.mantsch@marquette.edu Received 15 December 2010; revised 24 January 2011; accepted 2 February 2011 that stressors can reinstate extinguished cocaine seeking in rats (Ahmed and Koob, 1997; Erb et al, 1996).

One approach that can be used to investigate persistent drug-induced neuroplasticity related to stress-induced relapse involves the study of rats provided chronic daily prolonged access to cocaine for self-administration (SA) (Ahmed and Koob, 1998). We have previously reported that rats provided long access to cocaine for SA each day (longaccess rats), but not rats provided shorter drug access, show robust reinstatement in response to a stressor, uncontrollable electric footshock, when measured several weeks after SA (Mantsch et al, 2008a). This finding suggests that cocaine SA produces intake-dependent, long-term neuroadaptations that lead to a heightened susceptibility to engage in cocaine seeking during times of stress. Understanding the neurobiological processes that underlie the establishment and expression of stressor-induced cocaine use in addicted individuals should facilitate the development of new and better treatment approaches, particularly for subpopulations of cocaine addicts whose drug use is stress driven. 
A role for the neuropeptide, corticotropin-releasing factor (CRF), in stress-induced cocaine seeking has been established. CRF receptor antagonists block stress-induced reinstatement (Erb et al, 1998; Lee et al, 2003; Lu et al, 2001; Shaham et al, 1998; Wang et al, 2007) while delivery of CRF directly into the brain reinstates (Erb et al, 2006; Mantsch et al, 2008a). We have previously reported that, similar to what is observed with footshock, reinstatement by i.c.v. CRF is augmented following long-access SA (Mantsch et al, 2008a). These findings are consistent with reports that CRF regulation of addiction-related neurocircuitry requires a previous history of drug exposure (Wang et al, 2005). Interestingly, the role for CRF in cocaine seeking has been reported to depend on the reinstating stimulus. CRF antagonists block reinstatement following stress, but not following a priming injection of cocaine in rats with limited drug intake (Erb et al, 1998; Lee et al, 2003; Lu et al, 2001; Shaham et al, 1998; Wang et al, 2007; but see, Przegaliński et al, 2005). However, the contribution of CRF to the augmented stressor- and cocaine-induced reinstatement observed in rats with a history of cocaine SA under longaccess conditions remains to be determined. The reported ability of CRF antagonists to attenuate cocaine SA by longaccess, but not short-access rats (Specio et al, 2008) suggests that intake-dependent alterations within the CRF system may establish CRF regulation of cocaine responsiveness in a manner that promotes drug-seeking behavior. In this study, we examined the role of CRF in reinstatement by cocaine and footshock in rats with a history of longaccess SA using i.c.v. administration of the CRF receptor antagonist, $\alpha$-helical $\mathrm{CRF}_{9-41}$.

It has been proposed that hormonal stress responses associated with drug use contribute to addiction-related neuroplasticity through the regulation of CRF actions on neurocircuitry subserving motivation and reward (Kreek and Koob, 1998; Koob and Kreek, 2007). We have reported that an intact adrenal response at the time of earlier drug SA is necessary for the establishment of neuroadaptations that lead to heightened cocaine seeking (Mantsch and Katz, 2007; Mantsch et al, 2008b). Our findings are consistent with previous reports that eliminating cocaine-induced adrenal responses during the induction phase prevents the later expression of stress- and cocaine-induced sensitization (Rouge-Pont et al, 1995; Prasad et al, 1996, 1998; Przegaliński et al, 2000; de Jong et al, 2007). In this study, we examined the effects of eliminating the adrenal response to long-access cocaine SA through adrenalectomy along with diurnal corticosterone replacement (ADX/C) before 14 days of longaccess (ie, 6-h) SA on later i.c.v. CRF- and footshock-induced reinstatement. To confirm that the loss of adrenal activity at the time of earlier drug exposure and not later reinstatement testing contributed to effects on drug-seeking behavior, separate groups of rats were tested for reinstatement after undergoing ADX/C after a 14-day period of long-access SA, but before extinction training and reinstatement testing (ie, after SA-induced adaptations were already in place).

The results of this study suggest that stressor- but not cocaine-induced reinstatement in long-access rats is CRF dependent and that the establishment of later CRF and CRFdependent footshock-induced reinstatement requires increased adrenal, presumably glucocorticoid, activity at the time of earlier long-access cocaine SA.

\section{MATERIALS AND METHODS}

\section{Subjects}

Ninety-two male Sprague-Dawley rats (Harlan Laboratories, St Louis, MO), approximately 90 days old (325 g) were used. Rats were housed individually in a temperatureand humidity-controlled, AAALAC-accredited facility under a $12 \mathrm{~h} / 12 \mathrm{~h}$ reversed light/dark cycle (lights off at 0700 hours) and had access to food and water at all times. Procedures were carried out in accordance with the NIH Guide for the Care and Use of Laboratory Animals.

\section{Catheter Implantation}

Rats were implanted with indwelling silicon (Silastic; Dow Corning, Midland, MI; $0.64 \mathrm{~mm}$ i.d.; $1.19 \mathrm{~mm}$ o.d.) catheters under ketamine $\mathrm{HCl}(100 \mathrm{mg} / \mathrm{kg}$, i.p. $)$ and xylazine $(2 \mathrm{mg} / \mathrm{kg}$, i.p.) anesthesia (Mantsch et al, 2008b). Catheters were connected to back-mounted cannulae (Plastics One, Roanoke, VA) attached using dental acrylic to pieces of polypropylene monofilament surgical mesh (Atrium Medical, Hudson, NH) to permit connection of polyurethane delivery lines $(0.51 \mathrm{~mm}$ i.d. $\times 1.52 \mathrm{~mm}$ o.d.) encased in stainless-steel spring leashes (Plastics One). Lines were connected to syringes in pumps (Razel, Stamford, CT) via fluid swivels (Instech Lab., Plymouth Meeting, PA) suspended above the chambers. Swivel/leash assemblies were balanced to permit unrestrained movement. Rats recovered for 3 days before SA, which time they received acetaminophen $(480 \mathrm{mg} / \mathrm{l})$ in their drinking water.

\section{SA Apparatus}

Operant conditioning chambers encased in sound attenuating cubicles (MED-Associates, St Albans, VT) and equipped with retractable levers with stimulus lights located above each lever were used for SA. One lever and light were mounted on the front wall of the chamber. A second lever and light were located on the back wall.

\section{SA and Extinction}

Following recovery from surgery, rats were trained to selfadminister cocaine $(1.0 \mathrm{mg} / \mathrm{kg} / \mathrm{inf}$, i.v., NIDA Drug Supply Program, Bethesda, MD) by pressing a lever under an FR1 schedule during 2-h sessions, within which the active (front) lever was extended into the chamber and the corresponding stimulus light was illuminated. Pressing this lever resulted in a cocaine infusion $(200 \mu \mathrm{l}$ over $5.0 \mathrm{~s})$, followed by a 25 -s period during which the stimulus light was extinguished, but the lever remained extended. Inactive (back) lever responding was recorded, but had no programmed consequences. Once significant SA under the FR1 schedule was observed ( $>10$ infusions), the requirements for SA were gradually increased until rats were selfadministering under an FR4 schedule. After stable responding was observed under the FR4 schedule $(<10 \%$ variation from the mean over three sessions), rats underwent ADX/C or sham procedures and/or were provided access to cocaine during daily 6-h (long-access) sessions for 14 days. 
Experiment 1: Role of CRF in Cocaine- and Stress-Induced Reinstatement after Long-Access SA

Ten rats were tested for the role of CRF in cocaine- and stressor-induced reinstatement following SA using i.c.v. administration of the CRF-R $1 / 2$ receptor antagonist $\alpha$-helical $\mathrm{CRF}_{9-41}$ (Sigma-Aldrich, St Louis, MO) before reinstatement testing. At the time of catheterization, these rats were implanted with a $2.1-\mathrm{cm} 23$-gauge guide cannula into the left or right lateral ventricle using coordinates from Paxinos and Watson (1998): $-1.0 \mathrm{~mm}$ a/p bregma; $\pm 1.4 \mathrm{~mm} \mathrm{~m} / 1$ midline; and $-3.77 \mathrm{~mm} \mathrm{~d} / \mathrm{v}$ dura (Mantsch et al, 2008a). Injections were performed via a microinjector, which extended 1-mm below the tip of the guide. After recovery from surgery, rats were trained to self-administer and tested under long-access conditions for 14 days, followed by 10 days of extinction. After extinction, separate groups of rats were tested for reinstatement during 2-h sessions that followed a period of electric footshock $(n=5)$ or a cocaine challenge $(n=5) 10 \mathrm{~min}$ after i.c.v. delivery of $\alpha$-helical $\mathrm{CRF}_{9-41}(10 \mu \mathrm{g}$ in $1 \mu \mathrm{l}$ over $1 \mathrm{~min})$ or vehicle (sterile water). Each rat was tested twice for reinstatement in counterbalanced sequence, once with cocaine or footshock in combination with i.c.v. $\alpha$-helical $\mathrm{CRF}_{9-41}$ and once with vehicle. Before the second test, rats underwent an additional extinction session. Electric footshock was delivered though the stainless-steel grid floors of the SA chambers for $15 \mathrm{~min}$ before the 2 -h session, which was otherwise identical to extinction conditions. During the 15-min footshock period, the house light was illuminated and the levers were retracted and stimulus lights extinguished. Shocks $(0.5 \mathrm{~mA}, 0.5 \mathrm{~s}$ in duration) were delivered an average of every $40 \mathrm{~s}$ (range 10-70 s). We have reported that these parameters produce robust reinstatement after long-access, but not short-access, SA (Mantsch et al, 2008a). Cocaine-induced reinstatement testing was conducted for $2 \mathrm{~h}$ immediately following a cocaine injection $(10 \mathrm{mg} / \mathrm{kg}$, i.p.). Reinstatement was defined as responding on the previously active lever and compared with the preceding extinction session.

\section{Experiment 2: Effects of ADX/C on Footshock-Induced Reinstatement}

To examine the role of the adrenal response in the establishment and expression of footshock-induced reinstatement, rats underwent bilateral ADX via the dorsal approach under ketamine and xylazine anesthesia and received ADX/C (Mantsch and Katz, 2007) before or after 14 days of cocaine SA or received sham treatments. Diurnal corticosterone replacement consisted of s.c. implantation of a $25 \%$ corticosterone (Sigma-Aldrich) pellet in the nape of the neck to produce blood concentrations similar to those found at the nadir of the diurnal cycle along with inclusion of $0.025 \%$ corticosterone in the drinking water to emulate the circadian peak observed during the active (dark) phase, within which most drinking occurs (Jacobson et al, 1988). Pellets were made by melting a $1: 3$ corticosterone: cholesterol ratio mixture over a flame and pouring it into a mold, creating a $1.5 \times 0.5 \times 0.5 \mathrm{~cm}^{3}(l \times w \times h)$ pellet (Meyer et al, 1979). Corticosterone was dissolved in ethanol before introduction into the drinking water, resulting in a final ethanol concentration of $1 \mathrm{ml} / \mathrm{l}(0.0001 \%)$. To replace depleted sodium secondary to the loss of aldosterone as a result of $\mathrm{ADX}$, drinking water for all rats (ADX/C and sham) consisted of a $0.9 \% \mathrm{NaCl}$ solution. Corticosterone pellets were replaced every 7 days under sodium methohexital (1.5 mg, i.v.) sedation. Sham rats were implanted with $100 \%$ cholesterol pellets. Sham operations were identical to ADX surgeries, except that, once exposed, the adrenal glands were not removed. Before undergoing $\mathrm{ADX} / \mathrm{C}$ or sham procedures, rats were trained to self-administer cocaine during 2-h sessions. After recovery, rats were allowed to self-administer again until stable response patterns were re-established, at which time long-access SA testing began, followed by extinction and testing for footshock-induced reinstatement. A third group of rats was used to examine the effects $\mathrm{ADX} / \mathrm{C}$ after SA, but before extinction on later footshock-induced reinstatement. These rats underwent the ADX/C procedure after 14 days of SA and were allowed to recover before the 10-day extinction period and reinstatement testing.

\section{Experiment 3: Effects of ADX/C on CRF-Induced Reinstatement}

$\mathrm{ADX} / \mathrm{C}$ effects on reinstatement by i.c.v. CRF were tested in a separate group of rats implanted with a cannula into a lateral ventricle at the time of catheterization. Following recovery and SA training, these rats underwent $\mathrm{ADX} / \mathrm{C}$ or sham treatments before SA and extinction. After extinction, each rat was tested for reinstatement in response to two concentrations of CRF and sterile water vehicle in counterbalanced sequence. During reinstatement testing rats received an i.c.v. $1-\mu$ l infusion of CRF ( 0.5 or $1 \mu$ g; SigmaAldrich) or vehicle over a 1 -min period $15 \mathrm{~min}$ before placement into the chambers for $2 \mathrm{~h}$ (Mantsch et al, 2008a). A third group of rats underwent ADX/C after 14 days of SA and, following a 3-4 day recovery period, went through 10 days of extinction before testing for CRF-induced reinstatement. In all cases, rats with confirmed injection sites outside of the lateral ventricle were excluded from data analyses.

\section{Measurement of Plasma Corticosterone}

When possible, blood (100 $\mu$ l per sample) was acquired via the catheters for the measurement plasma corticosterone under basal conditions and during SA. Samples were acquired before (at 0800 hours, just after the start of the dark phase) and after the 6-h SA sessions (at 1400 hours) and at the corresponding baseline time points. In addition, samples were acquired after $2 \mathrm{~h}$ of SA (at $1000 \mathrm{~h}$ ) and at the corresponding baseline time from a separate group of rats for examination of corticosterone at an earlier time during the SA sessions. The days on which blood samples were taken varied across the 14-day test period such that about half of the rats were sampled during the first 7 days and the other half during the final 7 days of SA. In addition, 12 rats (six ADX/C and six sham) implanted with a lateral ventricle cannula were used to examine the plasma corticosterone responses to footshock and i.c.v. CRF. These rats underwent i.c.v. cannula implantation and $\mathrm{ADX} / \mathrm{C}$ or sham procedures before testing for footshock- and CRF-induced corticosterone responses. Corticosterone was measured using radioimmunoassay kits ( $\mathrm{MP}$ Biochemicals, Irvine, CA). 
Blood was collected on ice in tubes containing heparin and centrifuged to separate plasma, which was frozen at $-80^{\circ} \mathrm{C}$. Samples were analyzed in duplicate.

\section{Statistical Analyses}

Statistical analyses were conducted using Predictive Analytics SoftWare statistics software (SPSS, Chicago, IL). Statistical significance was determined using ANOVA, followed, when appropriate, by further analyses of main effects using ANOVA and/or post hoc testing using Bonferroni-corrected $t$-tests, unless indicated otherwise.

\section{RESULTS}

\section{Experiment 1: Role of CRF in Cocaine- and Stress-Induced Reinstatement after Long-Access SA}

Five rats were tested for the effects of i.c.v. $\alpha$-helical $\mathrm{CRF}_{9-41}$ on cocaine-induced reinstatement following long-access SA and five were tested for the effects of i.c.v. $\alpha$-helical $\mathrm{CRF}_{9-41}$ on reinstatement by footshock. Cocaine SA by the rats used for Experiment no. 1 is shown in Figure 1. As reported previously, a progressive escalation of SA was observed (one-way ANOVA; $F_{13,117}=2.917 ; P=0.001$ ), with a significant increase in SA on day 13 of testing (two-tailed Dunnett's $t$-test; $P=0.05)$. Extinction and cocaine- and footshock-induced reinstatement of cocaine seeking following i.c.v. administration of the CRF receptor antagonist $\alpha$-helical $\mathrm{CRF}_{9-41}(10 \mu \mathrm{g})$ or vehicle are shown in Figure 2. Reinstatement by footshock (Figure 2A), but not cocaine (Figure 2B), was blocked by i.c.v. delivery of $\alpha$-helical $\mathrm{CRF}_{9-41}$ in rats with a history of long-access SA. Two-way ANOVA showed significant overall footshock $\left(\mathrm{F}_{1,4}=7.726\right.$; $P<0.05)$ and cocaine $\left(F_{1,4}=9.146 ; P<0.05\right)$ reinstatement effects. A significant interaction was found between $\alpha$-helical $\mathrm{CRF}_{9-41}$ pretreatment and shock-induced $\left(\mathrm{F}_{1,4}=\right.$ 7.323; $P=0.05)$, but not cocaine-induced, reinstatement.

\section{Cocaine SA and Extinction in Rats used for Experiments} 2 and 3

Effects of ADX/C on cocaine SA. Cocaine SA by shamtreated rats $(n=28)$ and rats that underwent ADX/C before

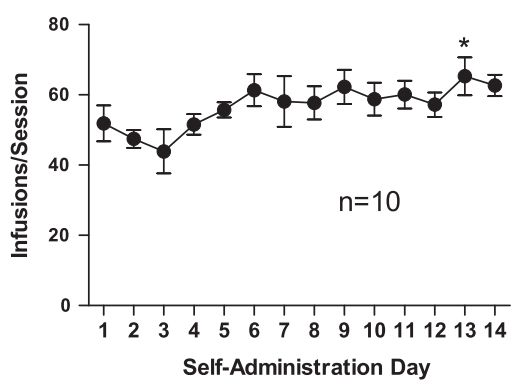

Figure I Cocaine self-administration (SA) under long-access conditions. Data represent intravenous (i.v.) cocaine (1.0 mg/kg/inf) SA (infusions $/ 6-\mathrm{h}$ session $\pm \mathrm{SE}$ ) in rats tested for the effects of intracerebroventricular (i.c.v.) $\alpha$-helical corticotropin-releasing factor $(\mathrm{CRF})_{9-41}$ on later cocaine- and electric footshock-induced reinstatement. Rats showed a progressive escalation of cocaine SA, with a significant increase in cocaine intake on day 13 of testing (two-tailed Dunnett's test vs SA day I; *P=0.05).
14 days of long-access SA ( $n=30$; pre-SA ADX) or after 14 days of $\mathrm{SA}(n=24$; post-SA ADX) is shown in Figure 3a. Data from rats tested for later footshock- and CRF-induced reinstatement were combined for this analysis. Two-way ANOVA showed a significant overall main effect of SA day $\left(\mathrm{F}_{13,1027}=10.400 ; P<0.001\right)$ and $\mathrm{ADX}$ condition $\left(\mathrm{F}_{2,79}=\right.$ 4.605; $P<0.05)$, but did not show a significant SA day $\times$ ADX condition interaction. SA was increased on days 4-14 compared with day $1(P<0.05)$ and, overall, SA was modestly, but significantly, reduced in rats that underwent $\mathrm{ADX} / \mathrm{C}$ before SA compared with rats that underwent ADX/ C after SA $(P<0.05)$, but, surprisingly, not compared with sham-treated controls. No differences across ADX/C conditions on the first day of SA testing were found.

\section{SA-Induced Increases in Plasma Corticosterone}

SA-induced increases in plasma corticosterone in shamtreated and ADX/C rats are shown in Figure 3b. As we did not acquire samples from every rat in each group at each time point, we used a $3 \times 3$ two-way independent measures ANOVA to examine corticosterone at three time points corresponding to the times just before SA testing (ie. at 0800 hours), $2 \mathrm{~h}$ into SA testing (ie, at 1000 hours), and just after the 6-h SA session (ie, at 1400 hours) under basal conditions and in response to SA. The ANOVA did not show a significant overall effect of time-of-day, although a clear diurnal pattern of corticosterone fluctuation was observed under basal conditions in sham-treated rats with peak levels at the 0800 hours time point corresponding to the start of the dark phase and the low point at 1400 hours, $6 \mathrm{~h}$ into the dark phase. A significant overall effect of treatment condition (baseline $v s$ sham SA vs ADX/C SA; $\left.\mathrm{F}_{2,182}=9.566 ; P<0.0001\right)$ and a significant treatment condition $\times$ time-of-day interaction $\left(\mathrm{F}_{4,186}=5.151 ; P<0.001\right)$ were observed. Comparison across treatments using one-way ANOVA at each of the three time showed significant main effects at the 1000 hours $\left(\mathrm{F}_{2,30}=\right.$ 11.833; $P<0.001)$ and 1400 hours $\left(\mathrm{F}_{2,65}=3.850 ; P<0.05\right)$, but not the 0800 hours (ie, pre-SA), time point. Overall
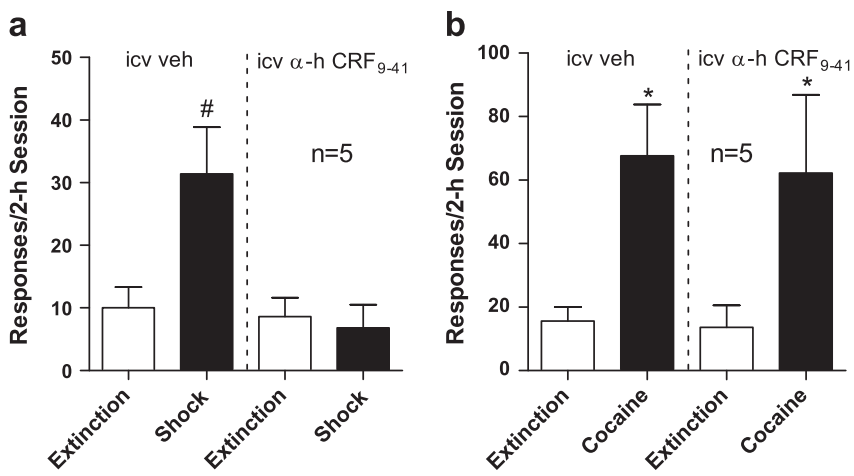

Figure 2 Central corticotropin-releasing factor (CRF) receptor antagonism blocks stress- but not cocaine-induced reinstatement. Data represent responding during the reinstatement sessions preceded by 15 -min of intermittent electric footshock $(n=5 ;$ a) or a $10 \mathrm{mg} / \mathrm{kg}$ (i.p.) cocaine challenge $(n=5 ; b)$ in rats pretreated with an intracerebroventricular (i.c.v.) injection of the CRF receptor antagonist $\alpha$-helical $\mathrm{CRF}_{9-4 \mathrm{I}}(\mathrm{I} 0 \mu \mathrm{g})$ or vehicle or during the corresponding extinction session. Footshock reinstated extinguished cocaine seeking following pretreatment with vehicle, but not $\alpha$-helical $\mathrm{CRF}_{9-41}$ $\left({ }^{\#} P<0.05\right.$ vs extinction and i.c.v. vehicle). By contrast, cocaine-induced reinstatement was observed following pretreatment with either $\alpha$-helical $\mathrm{CRF}_{9-41}$ or vehicle (*P $<0.05$ vs extinction). 

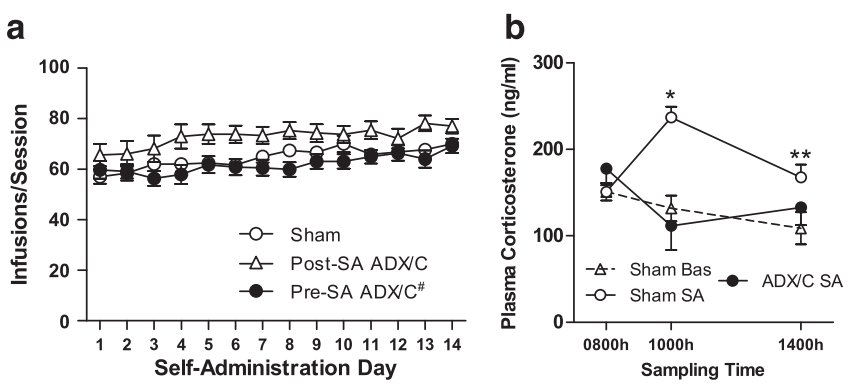

Figure 3 Cocaine self-administration (SA) and SA-induced increases in plasma corticosterone in sham and adrenalectomy and diurnal corticosterone replacement (ADX/C)-treated rats. Data in (a) represent intravenous (i.v.) cocaine SA (infusions/6-h session $\pm \mathrm{SE}$ ) in rats that underwent adrenalectomy and diurnal corticosterone replacement before 14 days of SA testing (pre-SA ADX/C; $n=30$ ) or after 14 days of SA, but before extinction and testing for corticotropin-releasing factor (CRF)- or footshockinduced reinstatement (post-SA ADX/C; $n=24$ ) or underwent a sham treatment $(n=28)$. Significant escalation of SA was observed in all groups and, overall, SA was reduced in pre-SA ADX/C rats relative to post-SA $A D X / C$ - but not sham-treated rats $\left({ }^{\#} P<0.05\right)$. Data in (b) represent plasma corticosterone (CORT) $(\mathrm{ng} / \mathrm{ml} \pm \mathrm{SE}$ ) measured at 0800 hours (a time corresponding to the start of the daily SA session), 1000 hours (a time corresponding to a point $2 \mathrm{~h}$ into the SA session), and 1400 hours (a time corresponding to the completion of the 6-h SA session) in shamtreated rats under basal conditions (Sham Baseline) or during SA (Sham baseline) or in ADX/C-treated rat during SA (ADX/C SA). In sham-treated rats, cocaine SA increased plasma corticosterone relative to basal levels. During $S A, A D X / C$ rats showed that corticosterone values were similar to baseline levels and significantly lower than levels during SA in shamtreated rats $(* P<0.001$ vs sham baseline and ADX/C SA; $* * P<0.05$ vs sham SA only).

corticosterone levels were significantly higher in sham-treated rats during SA compared with basal conditions $(P<0.001)$. $S A$-induced increases in corticosterone were prevented by $\mathrm{ADX} / \mathrm{C}$ treatment. Corticosterone levels were significantly reduced during $\mathrm{SA}$ in $\mathrm{ADX} / \mathrm{C}$ rats compared with shamtreated controls $(P<0.05)$. By contrast, corticosterone levels in $\mathrm{ADX} / \mathrm{C}$ rats during SA did not differ from basal corticosterone levels and did not differ between ADX/C rats during SA and baseline values in sham-treated rats. At the 1400 hours time point, corticosterone levels in self-administering sham rats were also significantly higher than that during sham baseline conditions $(P<0.05)$. However, the difference between sham and ADX/C SA rats at this time point did not reach statistical significance.

\section{Effects of ADX/C on Extinction Responding}

Extinction of cocaine SA in sham-treated rats $(n=28)$ and rats that underwent $\mathrm{ADX} / \mathrm{C}$ before 14 days of $\mathrm{SA}(n=30$; pre-SA ADX) or after 14 days of SA, but before extinction and reinstatement testing $(n=24)$, is shown in Figure 4. Two-way ANOVA showed significant main effects of extinction day (repeated measure; $\mathrm{F}_{9,711}=67.704 ; P<0.0001$ ) and ADX condition $\left(\mathrm{F}_{2,79}=7.29 ; P=0.001\right)$, but no ADX condition $\times$ extinction day interaction. As expected, responding progressively decreased across the 10 days of extinction training. Overall, responding was significantly lower in pre-SA $\mathrm{ADX}$ rats compared with rats that received sham treatments and rats that did not receive ADX/C until after the SA phase of the study, but before extinction (Figure $4 \mathrm{~b}$ ), suggesting that adrenal activity at the time of cocaine SA, but not during extinction itself, contributed to drug-seeking behavior during the extinction sessions.

\section{Experiment 2: Effects of ADX/C on Footshock-Induced Reinstatement}

The effects of ADX/C on footshock-induced reinstatement were examined in rats that underwent $\mathrm{ADX} / \mathrm{C}$ before 14 days of long-access SA $(n=18)$, rats that underwent ADX/C after 14 days of SA, but before extinction and reinstatement $(n=15)$, and sham-treated rats $(n=16)$ and are shown in Figure 5a. A two-way footshock reinstatement $\times$ ADX condition ANOVA that included rats from all three ADX groups (ie, sham, pre-SA ADX/C, and post-SA $A D X / C)$ showed significant main effects of shock $\left(\mathrm{F}_{1,46}=27.730 ; \quad P<0.001\right)$ and $\mathrm{ADX}$ treatment $\left(\mathrm{F}_{2,46}=\right.$ $3.768 ; P<0.05)$ on cocaine seeking as well as a significant interaction between footshock and ADX treatment $\left(\mathrm{F}_{2,46}=3.231 ; \quad P<0.05\right)$. Post hoc testing showed that significant footshock-induced reinstatement occurred in sham-treated and post-SA ADX/C, but not pre-ADX/C rats $(P<0.05$ vs extinction). Further, footshock-induced lever pressing was significantly reduced in pre-SA ADX/C, but not post-SA ADX/C rats, compared with sham controls $(P<0.01)$, even though responding under extinction conditions was not different.

\section{Effects of ADX/C on Footshock-Induced Increases in Plasma Corticosterone}

To confirm that our ADX/C approach eliminated footshockinduced increases in plasma corticosterone, the response to footshock following sham treatment or $\mathrm{ADX} / \mathrm{C}$ was determined in a separate group of 12 rats $(n=6, \mathrm{ADX} / \mathrm{C}$ and $n=6$, sham) and is shown in Figure $5 \mathrm{~b}$. As expected, $\mathrm{ADX} / \mathrm{C}$ eliminated footshock-induced increases in corticosterone. Two-way ANOVA showed a significant overall effect of footshock $\left(\mathrm{F}_{1,10}=13.777\right)$ and $\mathrm{ADX}$ condition $\left(\mathrm{F}_{1,10}=\right.$ 67.797) on plasma corticosterone $(P<0.001$ for each) and a significant shock $\times$ ADX condition interaction $\left(\mathrm{F}_{1,10}=\right.$ $25.199, P=0.001)$. Footshock significantly increased plasma corticosterone in sham-treated $(P<0.01$ vs baseline), but not ADX/C, rats. Further, plasma corticosterone following footshock was significantly higher in sham-treated compared with ADX/C rats $(P<0.05)$, whereas differences in basal corticosterone levels were not observed.

\section{Experiment 3: Effects of ADX/C on CRF-Induced Reinstatement}

As we have previously reported that, like footshock, reinstatement by i.c.v. CRF is augmented after long-access SA (Mantsch et al, 2008a) and because shock-induced reinstatement in rats after long-access SA is CRF dependent (Figure 2), we examined the role of adrenal activation at the time of earlier SA testing on later CRF-induced reinstatement. The effects of ADX/C on CRF-induced reinstatement were examined in 12 rats that underwent $\mathrm{ADX} / \mathrm{C}$ before 14 days of $\mathrm{SA}$, nine rats that underwent $\mathrm{ADX} / \mathrm{C}$ after 14 days of SA, but before extinction and reinstatement, and 14 sham-treated rats and are shown in Figure 6a. Two-way $\mathrm{CRF} \times \mathrm{ADX}$ condition ANOVA showed significant main 

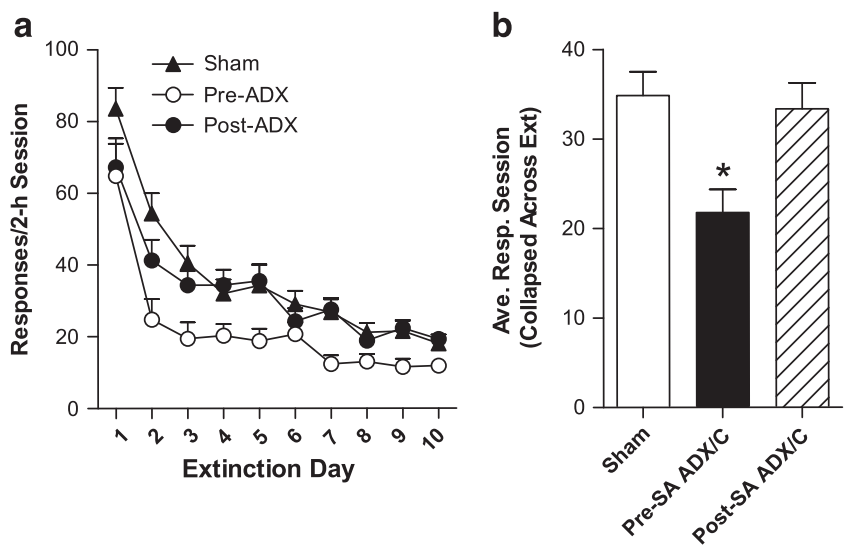

Figure 4 Extinction of cocaine self-administration (SA) in sham- and adrenalectomy and diurnal corticosterone replacement (ADX/C)-treated rats. Data represent responding during extinction in rats that underwent ADX and corticosterone replacement before 14 days of SA testing (preSA ADX/C; $n=30$ ) or after 14 days of SA but before (post-SA ADX/C; $n=24)$, or sham controls $(n=28)$ shown as daily responding during each of the 10 days of extinction (responses/2-h session $\pm \mathrm{SE}$; a) or total responding collapsed across all 10 days ( \pm SE; b). Overall, extinction responding was significantly decreased in pre-SA ADX/C rats compared with either post-SA ADX/C rats or sham-treated controls $(* P<0.05 ; b)$.

effects of CRF delivery $\left(\mathrm{F}_{2,60}=5.396 ; P<0.01\right)$ and ADX condition $\left(\mathrm{F}_{2,30}=3.382 ; P<0.05\right)$, but did not show a significant $\mathrm{CRF} \times \mathrm{ADX}$ condition interaction. Post hoc testing showed overall dose-dependent reinstatement by $\mathrm{CRF}$, with significant reinstatement observed at the $0.5 \mu \mathrm{g}$ CRF dose $(P<0.05)$, but not the $1.0 \mu \mathrm{g}$ dose $(P=0.058)$, when compared with vehicle pretreatment. Overall, reinstatement was significantly reduced in the pre-SA ADX/C group compared with sham controls $(P<0.05)$, but not in the post-SA ADX/C group. To determine if CRF induced reinstatement in each of the ADX groups, a planned analysis of reinstatement was conducted using one-way repeated measures ANOVA within each ADX group. Significant dose-dependent CRF-induced reinstatement was found in sham-treated $(P<0.01 v s$ vehicle), but not pre- or post-SA $\mathrm{ADX} / \mathrm{C}$, rats.

\section{Effects of ADX/C on I.C.V. CRF-Induced Increases in Plasma Corticosterone}

To confirm that our ADX/C approach eliminated the corticosterone response to CRF, responses to CRF following sham or ADX treatments were determined in 12 rats $(n=6$, $\mathrm{ADX} / \mathrm{C}$ and $n=6$, sham) and are shown in Figure $6 \mathrm{~b}$. $\mathrm{ADX} / \mathrm{C}$ eliminated the corticosterone response to 0.5 and $1.0 \mu \mathrm{g} / \mathrm{kg}$ CRF. Two-way CRF treatment $\times$ ADX condition ANOVA showed a significant overall effects of CRF $\left(\mathrm{F}_{2,20}=\right.$ 34.709; $P<0.001)$ and $\mathrm{ADX} / \mathrm{C}\left(\mathrm{F}_{1,10}=88.102 ; P<0.001\right)$, and a significant $\mathrm{CRF}$ treatment $\times \mathrm{ADX}$ condition interaction $\left(\mathrm{F}_{2,20}=26.676, P<0.001\right)$. Further analysis using one-way ANOVA within each ADX condition showed that each CRF dose increased corticosterone in sham-treated $(P<0.01$ vs baseline), but not $\mathrm{ADX} / \mathrm{C}$, rats. Further, corticosterone was significantly higher following either i.c.v. CRF dose in shamtreated rats compared with $\mathrm{ADX} / \mathrm{C}$ rats $(P<0.001)$, whereas differences in basal levels were not observed.
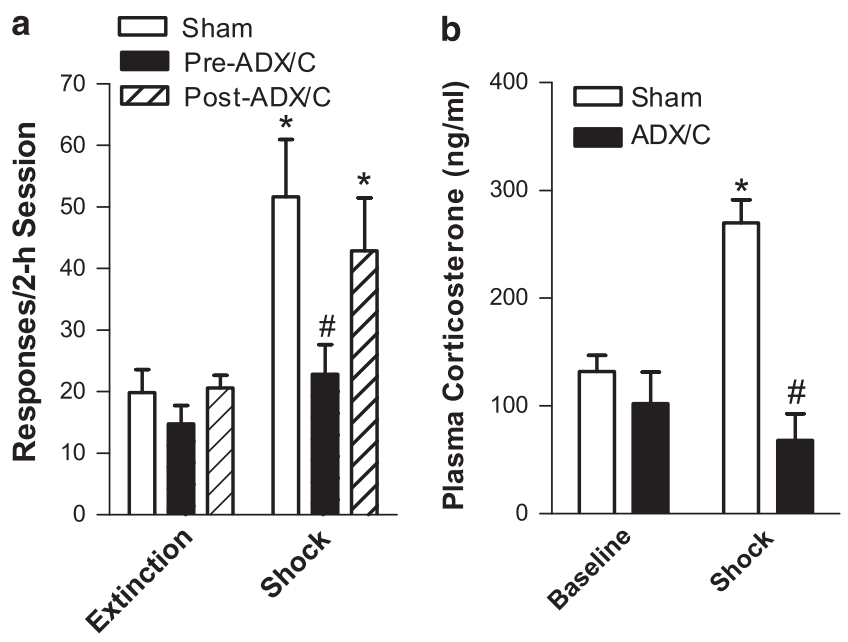

Figure 5 Stressor-induced reinstatement and increases in plasma corticosterone in sham- and adrenalectomy and diurnal corticosterone replacement $(A D X / C)$-treated rats. Data in (a) represent responding during the reinstatement sessions preceded by 15 min of intermittent electric footshock or during the preceding extinction session in pre-selfadministration (SA) ADX/C $(n=18)$-, post-SA ADX/C $(n=15)-$, and sham-treated $(n=16)$ rats following long-access (6-h daily) SA. Footshockinduced reinstatement was prevented by ADX/C before (pre-SA ADX/C), but not after (post-SA ADX/C) long-access cocaine SA (*significant reinstatement, $P<0.05$ vs extinction; "significant decrease vs sham, $P<0.05)$. Data in (b) represent the effects of footshock on plasma corticosterone $(\mathrm{ng} / \mathrm{ml} \pm \mathrm{SE})$ in ADX/C $(n=6)$ - and sham-treated $(n=6)$ rats. $A D X / C$ prevented footshock-induced increases in plasma corticosterone ( $P<0.0$ I shock vs baseline; ${ }^{\#} P<0.00$ I ADX/C vs sham).

\section{DISCUSSION}

We have previously reported that reinstatement in response to a stressor, uncontrollable footshock, is observed in rats with a history of long-access cocaine SA $(14 \times 6 \mathrm{~h}$ per day $)$, but not in rats with a history of short-access SA $(14 \times 2 \mathrm{~h}$ per day; Mantsch et al, 2008a). The establishment of stressinduced reinstatement in long-access rats is likely attributable to intake-dependent alterations in neurobiological processes regulated by the neuropeptide CRF, as (1) shockinduced reinstatement in long-access rats is blocked by i.c.v. administration of the CRF receptor antagonist, $\alpha$-helical $\mathrm{CRF}_{9-41}$ (Figure 2); and (2) reinstatement by i.c.v. CRF is also augmented following long-access SA (Mantsch et al, 2008a). Cocaine SA under long-access conditions produces robust and prolonged increases in plasma corticosterone (Mantsch et al, 2003, 2007), and elimination of the adrenal response to long-access SA attenuates later cocaine-induced reinstatement (Mantsch et al, 2008b). In this paper, we show that CRF-dependent stress-induced reinstatement and reinstatement by CRF also rely on an intact adrenal response at the time of earlier long-access SA. However, ADX/C after long-access SA, but before extinction and reinstatement, failed to alter shock-induced reinstatement and only modestly suppressed reinstatement by CRF despite eliminating shock- and CRF-induced increases in corticosterone. Thus, although long-access SA increases stress-induced activation of the HPA axis (Mantsch et al, 2007), the augmented glucocorticoid response does not contribute to stress-induced cocaine seeking. These data suggest that an activated adrenal, presumably glucocorti- 

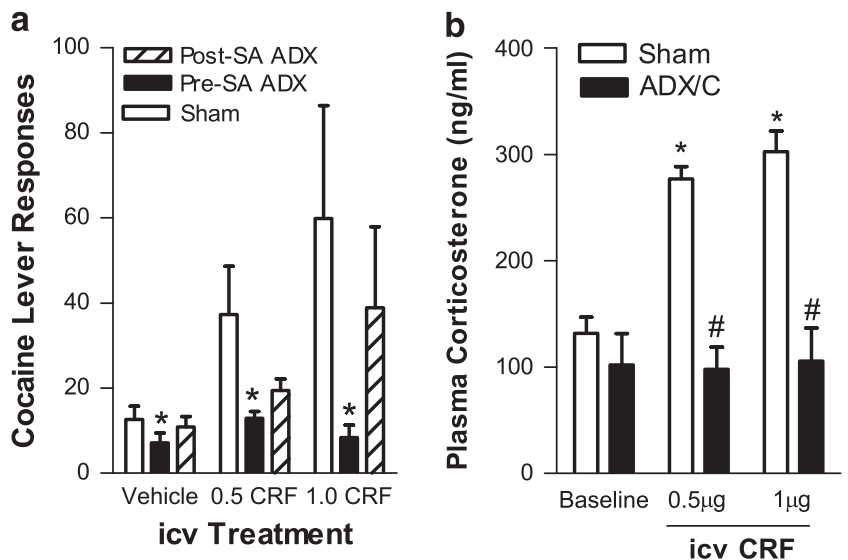

Figure 6 Corticotropin-releasing factor (CRF)-induced reinstatement and increases in plasma corticosterone in sham and adrenalectomy and diurnal corticosterone replacement (ADX/C)-treated rats. Data in (a) represent responding during the reinstatement sessions preceded by intracerebroventricular (i.c.v.) injections of CRF ( 0.5 or I $\mu \mathrm{g})$ or vehicle in pre-self-administration (SA) ADX/C $(n=12)$-, post-SA ADX/C $(n=9)$-, and sham-treated $(n=14)$ rats following long-access (6-h daily) SA. Overall, CRF-induced reinstatement was reduced by ADX/C before (preSA ADX/C), but not after (post-SA ADX/C) long-access cocaine SA compared with sham-treated rats (*significant overall decrease vs sham; $P<0.05)$. Data in (b) represent the effects of i.c.v. CRF on plasma corticosterone $(\mathrm{ng} / \mathrm{ml} \pm \mathrm{SE})$ in ADX/C $(n=6)$ - and sham-treated $(n=6)$ rats. $A D X / C$ prevented $C R F-i n d u c e d$ increases in plasma corticosterone ( $P<0.0$ I CRF vs baseline; ${ }^{*} P<0.0$ I, ADX/C vs sham).

coid, response at the time of cocaine use is necessary for establishing neuroplasticity involving CRF-responsive systems and leads to heightened susceptibility to later CRF-dependent stress-induced relapse.

\section{Stressor- but not Cocaine-Induced Reinstatement is CRF Dependent}

Previous studies have implicated CRF in cocaine abuse (Sarnyai et al, 2001; Shalev et al, 2010). CRF receptor antagonists reduce cocaine SA (Goeders and Guerin, 2000) and these reductions are greater after SA under long-access conditions, implying that there is an intake-dependent upregulation of the CRF system (Specio et al, 2008). For reinstatement, the role for CRF appears to depend on the reinstating stimulus. CRF is required for cocaine seeking induced by stress, but not a cocaine challenge (Erb et al, 1998; Lee et al, 2003; Lu et al, 2001; Shaham et al, 1998; Wang et al, 2007; but see, Przegaliński et al, 2005). Stressinduced reinstatement following heroin (Shaham et al, 1997), alcohol (Lê et al, 2000), and nicotine (Bruijnzeel et al, 2009) SA has also been reported to be CRF dependent. We extend these findings by showing that i.c.v. administration of the CRF receptor antagonist $\alpha$-helical $\mathrm{CRF}_{9-41}$ blocks reinstatement by shock, but not cocaine, in rats with a history of long-access SA. It should be noted that we only examined the effects of $\alpha$-helical $\mathrm{CRF}_{9-41}$ on reinstatement by a single, relatively high cocaine dose. Confirmation that $\mathrm{CRF}$ is not involved in cocaine-induced reinstatement will require testing for antagonist effects across a wider cocaine dose range.

\section{Adrenal Responses during SA are Required for Later CRF- and Stress-Induced Reinstatement}

Our findings suggest that an intact adrenal response at the time of long-access cocaine SA is required for later CRF-dependent stressor-induced reinstatement. Eliminating the adrenal response via ADX/C before long-access SA prevented later reinstatement by footshock or CRF. However, ADX/C treatment after a 14-day period of long-access SA, but before extinction and reinstatement, did not. Considering the role for CRF in footshock-induced reinstatement and our earlier finding that CRF-induced reinstatement is increased after long-access SA (Mantsch et al, 2008a), we hypothesized that the augmentation of reinstatement was attributable to an adrenal-dependent enhancement of CRF regulation of cocaine seeking. Accordingly, CRF-induced reinstatement was also prevented when rats underwent $\mathrm{ADX} / \mathrm{C}$ before, but not after, SA testing.

The adrenal requirement for the establishment of later stress- and CRF-induced reinstatement likely involves SA-induced increases in glucocorticoid production. Glucocorticoids secreted as a consequence of activation of the HPA axis play a critical role in physiological responses that enable organisms to effectively adapt to and cope with stressors (de Kloet et al, 2008) and have been proposed to participate in addiction-related processes (Piazza and Le Moal, 1996; Kreek and Koob, 1998; Marinelli and Piazza, 2002; Koob and Kreek, 2007). Glucocorticoid receptors are found in brain regions implicated in addiction (eg, the ventral tegmental area (VTA) and ventral striatum; Harfstrand et al, 1986), where repeated/prolonged elevation of glucocorticoids has been reported to induce morphological changes that may have long-term implications for cocaine seeking (Wellman, 2001; Morales-Medina et al, 2009). Consistent with this, elevated corticosterone has been reported to contribute to the stress-induced facilitation of the acquisition of cocaine SA (Campbell and Carroll, 2001; Goeders and Guerin, 1996; Mantsch et al, 1998), cocaineand stress-induced sensitization of cocaine's locomotorstimulating effects (Prasad et al, 1996, 1998; Rouge-Pont et al, 1995; Przegaliński et al, 2000; Wei et al, 2004; de Jong et al, 2007), and stress-induced escalation of cocaine SA (Mantsch and Katz, 2007). Like stress, cocaine SA elevates circulating glucocorticoid levels in rats (Galici et al, 2000; Mantsch et al, 2003), monkeys (Broadbear et al, 1999a), and human addicts (Ward et al, 1999). Not surprisingly, when rats self-administer cocaine under long-access conditions, the increase in corticosterone is prolonged, matching the duration of drug exposure and potentially rendering these rats more susceptible to later cocaine seeking (Mantsch et al, 2003, 2008b).

\section{Role of Glucocorticoids in Stress- and CRF-Induced Reinstatement}

In contrast to the effects of ADX/C before SA, ADX/C after long-access cocaine SA did not alter footshock-induced reinstatement, despite eliminating the corticosterone response to shock. This is consistent with reports that acute stress-induced increases in corticosterone are not necessary for reinstatement following cocaine or heroin SA (Shaham 
et al, 1997; Erb et al, 1998; Shalev et al, 2006). These findings parallel clinical reports that although drug-, cue- and stress-induced drug craving are accompanied by activation of the HPA axis (Berger et al, 1996; Ward et al, 1999; Sinha et al, 2003), pharmacological inhibition of glucocorticoid secretion has little or no effect on evoked craving in cocaine-dependent individuals (Harris et al, 2004; Winhusen et al, 2005). Although significant reductions in CRF-induced reinstatement were not observed in rats that underwent $\mathrm{ADX} / \mathrm{C}$ after long-access SA, cocaine seeking in these rats tended to be reduced, particularly at the lower (ie, $0.5 \mu \mathrm{g}$ ) CRF dose when compared with sham levels and significant reinstatement relative to vehicle treatment was not observed. For this reason, we are reluctant to rule out the possibility that the acute glucocorticoid response to CRF delivery contributed to reinstatement.

\section{Role for SA-Induced Adrenal Responses in Cocaine $\mathrm{SA}$ and Escalation}

Consistent with previous findings (Ahmed and Koob, 1998; Mantsch et al, 2004), a progressive escalation of cocaine intake was observed with repeated long-access SA. It has been suggested that escalated SA reflects the loss of control over drug use that is central to human cocaine addiction. As reported previously (Mantsch and Katz, 2007; Mantsch et al, 2008b), ADX/C failed to alter SA before escalation (ie, on the first day of testing), consistent with reports in monkeys and human addicts that increased glucocorticoid secretion by cocaine is not necessary for its acute reinforcing effects (Broadbear et al, 1999b; Ward et al, 1999). Others have shown that complete elimination of glucocorticoids by surgical or pharmacological $\mathrm{ADX}$ in the absence of corticosterone replacement attenuates cocaine SA in rats (Goeders and Guerin, 1996; Deroche et al, 1997). However, as was the case in this study, SA is restored when diurnal patterns of circulating corticosterone levels are re-established (Deroche et al, 1997).

We previously reported that, despite the lack of an initial effect on SA, ADX/C slows the escalation of SA that emerges under long-access conditions (Mantsch et al, 2008b). In this study, escalation was observed in both $\mathrm{ADX} / \mathrm{C}$ and sham-treated rats. However, modest, but significant overall reductions in SA were observed in pre-SA ADX/C rats when compared with post-SA $\mathrm{ADX} / \mathrm{C}$, but not sham, rats. It is notable that, although not statistically significant, SA in sham-treated rats was also reduced compared with post-SA $\mathrm{ADX} / \mathrm{C}$ rats, suggesting that nonspecific effects of the surgical procedure may have contributed to the difference.

\section{Potential Role of Non-Glucocorticoid Adrenal Responses}

Although we presume that the effects of ADX were attributable to prevention of the SA-induced glucocorticoid response, we cannot rule out the possibility that elimination of other adrenal hormones, including epinephrine released from the adrenal medulla or adrenal cortical steroids such as aldosterone, dehydroepiandrosterone, and deoxycorticosterone, contributed to our effects. It has been reported that the prevention of cocaine-induced behavioral sensitization in mice by surgical $\mathrm{ADX}$ is reversed if both corticosterone and epinephrine are co-administered with cocaine during induction, suggesting a potential cooperative role between glucocorticoids and epinephrine in the establishment of cocaine-induced neuroplasticity (de Jong et al, 2009).

\section{Effects of $\mathrm{ADX} / \mathrm{C}$ on Extinction after SA}

Despite minimal differences in drug intake, extinction responding was significantly reduced in rats that underwent ADX/C before SA. As rats that did not undergo ADX/C until after SA did not display similar reductions in extinction responding, these findings suggest that adrenal responses at the time of earlier SA likely led to an overall increase in responding during extinction. To the extent that adrenaldependent alterations in motivation to engage in cocaine seeking contributed to augmented reinstatement, it is possible that such changes also resulted in heightened drug seeking during extinction. Alternatively, adrenal activation during SA may promote the formation and/or consolidation of drug-related memories. A role for glucocorticoids in memory consolidation has been established (Sandi, 1998; Roozendaal, 2002). The extent to which this may have contributed to the attenuation of later reinstatement is unclear.

\section{Adaptations in CRF Systems and Heightened Susceptibility to Stress-Induced Drug Seeking}

Our findings that CRF-induced reinstatement is augmented in an intake-dependent manner following SA is consistent with reports that the locomotor and c-fos responses to i.c.v. CRF are increased after repeated cocaine (Erb et al, 2003, 2005). Repeated cocaine also produces widespread alterations in CRF receptor binding (Goeders et al, 1990) and increases CRF responsiveness throughout the brain, including in the lateral septum (Liu et al, 2005), hippocampus (Guan et al, 2009), amygdala (Orozco-Cabal et al, 2008; Erb et al, 2005; Pollandt et al, 2006), VTA (Wang et al, 2005; Hahn et al, 2009), and bed nucleus of the stria terminalis (BNST; Francesconi et al, 2009). These latter two regions (ie, the VTA and BNST) have been implicated in CRFinduced cocaine seeking (Erb and Stewart, 1999; Erb et al, 2001; Wang et al, 2005) and may therefore represent sites at which cocaine-induced adaptations that contribute to reinstatement occur. Although our findings suggest that heightened stress-induced reinstatement is largely attributable to increased CRF responsiveness related to alterations in receptors or downstream processes, others have reported alterations in basal and evoked CRF expression and release in a number of brain regions, most notably the amygdala, following chronic cocaine delivery (Richter et al, 1995; Richter and Weiss, 1999; Zorrilla et al, 2001; Zhou et al, 2003).

\section{Glucocorticoid Regulation of CRF Actions}

Glucocorticoid regulation of CRF actions has been reported. In contrast to the hypothalamus, where chronically elevated corticosterone reduces $\mathrm{CRF}$ production, corticosterone augments basal and stress-evoked increases in CRF mRNA in brain regions implicated in stressor-induced cocaine seeking (ie, amygdala, BNST, prefrontal cortex; Makino et al, 1994a, b, 1995; Shepard et al, 2006; Merali et al, 2008). 
These effects have been shown to contribute to augmented CRF-induced behavioral responses (Lee et al, 1994; Shepard et al, 2000). Glucocorticoids also regulate CRF receptor expression. Although regulation of CRF receptor expression within the hypothalamus and pituitary is primarily inhibitory (Kageyama et al, 2003; Chen et al, 2005), effects in non-hypothalamic brain regions vary, consistent with the glucocorticoid regulation of CRF mRNA (Makino et al, 1995; Schulkin et al, 1998). Adrenal-dependent neuroplasticity may also involve brain regions downstream from sites of CRF action. We have found that the augmentation of CRF-independent cocaine-induced reinstatement after longaccess SA is also prevented by pre-SA ADX/C (Mantsch et al, 2008b), suggesting that adrenal-dependent adaptations in brain regions that represent a final common pathway for stimuli that induce cocaine seeking may underlie augmented reinstatement. Accordingly, it has been reported that glucocorticoid receptors in dopaminoceptive neurons, likely in the nucleus accumbens, contribute to drug seeking following repeated cocaine delivery, but are not necessary for responses to acute cocaine (Deroche-Gamonet et al, 2003; Ambroggi et al, 2009).

\section{Conclusions}

To summarize, this study suggests that adrenal-dependent alterations in CRF responsiveness underlie the increased susceptibility to stress-induced relapse that emerges with repeated cocaine use. Understanding the mechanisms through which adrenal activation promotes CRF regulation of cocaine seeking should provide valuable insight into the addiction process and aid in the development of new approaches for the treatment of cocaine addicts.

\section{ACKNOWLEDGEMENTS}

This work was supported by National Institute on Drug Abuse (NIDA) Grant numbers DA15758 and DA025617. We acknowledge Eric Katz, Joseph Serge, Chad Seubert and Geng Lee for their technical assistance. The authors received financial support or compensation as follows: John $\mathrm{R}$ Mantsch is a Founder and past Director of as well as a consultant for and stockholder in Promentis Pharmaceuticals and has served as a consultant for WIL Research (Ashland, $\mathrm{OH}$ ). He has received research support from the $\mathrm{NIH}$ and the State of Wisconsin Biotechnology Alliance. $\mathrm{He}$ is a full-time employee of Marquette University. David A Baker is a Founder and Director as well as a consultant for and stockholder in Promentis Pharmaceuticals. He has received research support from the $\mathrm{NIH}$, the State of Wisconsin Biotechnology Alliance, and the National Alliance for Research on Schizophrenia and Addiction. $\mathrm{He}$ is a full-time employee of Marquette University. Evan Graf, Michael Hoks, Jose Sierra, Jean Baumgardner, Colin Bohr, and Oliver Vranjkovic were employees of Marquette University at the time that these studies were completed.

\section{DISCLOSURE}

The authors declare no conflict of interest.

\section{REFERENCES}

Ahmed SH, Koob GF (1997). Cocaine- but not food-seeking behavior is reinstated by stress after extinction. Psychopharmacology 132: 289-295.

Ahmed SH, Koob GF (1998). Transition from moderate to excessive drug intake: change in hedonic set point. Science 282: 298-300.

Ambroggi F, Turiault M, Milet A, Deroche-Gamonet V, Parnaudeau S, Balado E et al (2009). Stress and addiction: glucocorticoid receptor in dopaminoceptive neurons facilitates cocaine seeking. Nat Neurosci 12: 247-249.

Berger SP, Hall S, Mickalian JD, Reid MS, Crawford CA, Delucchi K et al (1996). Haloperidol antagonism of cue-elicited cocaine craving. Lancet 347: 504-508.

Broadbear JH, Winger G, Cicero TJ, Woods JH (1999a). Effects of self-administered cocaine on plasma adrenocorticotropic hormone and cortisol in male rhesus monkeys. J Pharmacol Exp Ther 289: 1641-1647.

Broadbear JH, Winger G, Woods JH (1999b). Cocaine-reinforced responding in rhesus monkeys: pharmacological attenuation of the hypothalamic-pituitary-adrenal axis response. J Pharmacol Exp Ther 290: 1347-1355.

Bruijnzeel AW, Prado M, Isaac S (2009). Corticotropin-releasing factor-1 receptor activation mediates nicotine withdrawalinduced deficit in brain reward function and stress-induced relapse. Biol Psychiatry 66: 110-117.

Campbell UC, Carroll ME (2001). Effects of ketoconazole on the acquisition of intravenous cocaine self-administration under different feeding conditions in rats. Psychopharmacology 154: 311-318.

Chen A, Perrin M, Brar B, Li C, Jamieson P, Digruccio M et al (2005). Mouse corticotropin-releasing factor receptor type 2alpha gene: isolation, distribution, pharmacological characterization and regulation by stress and glucocorticoids. Mol Endocrinol 19: 441-458.

de Jong IE, Oitzl MS, de Kloet ER (2007). Adrenalectomy prevents behavioural sensitisation of mice to cocaine in a genotypedependent manner. Behav Brain Res 177: 329-339.

de Jong IE, Steenbergen PJ, de Kloet ER (2009). Behavioral sensitization to cocaine: cooperation between glucocorticoids and epinephrine. Psychopharmacology 204: 693-703.

de Kloet ER, de Jong IE, Oitzl MS (2008). Neuropharmacology of glucocorticoids: focus on emotion, cognition and cocaine. Eur J Pharmacol 585: 473-482.

Deroche V, Marinelli M, Le Moal M, Piazza PV (1997). Glucocorticoids and behavioral effects of psychostimulants. II. Cocaine intravenous self-administration and reinstatement depend on glucocorticoid levels. J Pharmacol Exp Ther 281: 1401-1407.

Deroche-Gamonet V, Sillaber I, Aouizerate B, Izawa R, Jaber M, Ghozland S et al (2003). The glucocorticoid receptor as a potential target to reduce cocaine abuse. J Neurosci 23: 4785-4790.

Erb S, Funk D, Le AD (2003). Prior, repeated exposure to cocaine potentiates locomotor responsivity to central injections of corticotropin-releasing factor (CRF) in rats. Psychopharmacology 170: 383-389.

Erb S, Funk D, Lê AD (2005). Cocaine pre-exposure enhances CRF-induced expression of c-fos mRNA in the central nucleus of the amygdala: an effect that parallels the effects of cocaine preexposure on CRF-induced locomotor activity. Neurosci Lett 383: 209-214.

Erb S, Petrovic A, Yi D, Kayyali H (2006). Central injections of CRF reinstate cocaine seeking in rats after postinjection delays of up to $3 \mathrm{~h}$ : an influence of time and environmental context. Psychopharmacology 187: 112-120.

Erb S, Salmaso N, Rodaros D, Stewart J (2001). A role for the CRFcontaining pathway from central nucleus of the amygdala to bed 
nucleus of the stria terminalis in the stress-induced reinstatement of cocaine seeking in rats. Psychopharmacology 158: 360-365.

Erb S, Shaham Y, Stewart J (1996). Stress reinstates cocaineseeking behavior after prolonged extinction and a drug-free period. Psychopharmacology 128: 408-412.

Erb S, Shaham Y, Stewart J (1998). The role of corticotropin-releasing factor and corticosterone in stress- and cocaine-induced relapse to cocaine seeking in rats. J Neurosci 18: 5529-5536.

Erb S, Stewart J (1999). A role for the bed nucleus of the stria terminalis, but not the amygdala, in the effects of corticotropinreleasing factor on stress-induced reinstatement of cocaine seeking. J Neurosci 19: RC35.

Francesconi W, Berton F, Repunte-Canonigo V, Hagihara K, Thurbon D, Lekic D et al (2009). Protracted withdrawal from alcohol and drugs of abuse impairs long-term potentiation of intrinsic excitability in the juxtacapsular bed nucleus of the stria terminalis. J Neurosci 29: 5389-5401.

Galici R, Pechnick RN, Poland RE, France CP (2000). Comparison of noncontingent versus contingent cocaine administration on plasma corticosterone levels in rats. Eur J Pharmacol 387: 59-62.

Goeders NE, Bienvenu OJ, De Souza EB (1990). Chronic cocaine administration alters corticotrophin releasing factor receptors in the rat brain. Brain Res 531: 322-328.

Goeders NE, Guerin GF (1996). Effects of surgical and pharmacological adrenalectomy on the initiation and maintenance of intravenous cocaine self-administration in rats. Brain Res 25: 145-152.

Goeders NE, Guerin GF (2000). Effects of the CRH receptor antagonist CP-154,526 on intravenous cocaine self-administration in rats. Neuropsychopharmacology 23: 577-586.

Guan X, Zhang R, Xu Y, Li S (2009). Cocaine withdrawal enhances long-term potentiation in rat hippocampus via changing the activity of corticotropin-releasing factor receptor subtype 2 . Neuroscience 161: 665-670.

Hahn J, Hopf FW, Bonci A (2009). Chronic cocaine enhances corticotropin-releasing factor-dependent potentiation of excitatory transmission in ventral tegmental area dopamine neurons. J Neurosci 29: 6535-6544.

Harfstrand A, Fuxe K, Cintra A, Agnati LF, Zini I, Wikstrom AC et al (1986). Glucocorticoid receptor immunoreactivity in monoaminergic neurons of rat brain. Proc Natl Acad Sci USA 83: 9779-9783.

Harris DS, Batki SL, Berger SP (2004). Fluoxetine attenuates adrenocortical but not subjective responses to cocaine cues. $\mathrm{Am}$ J Drug Alcohol Abuse 30: 765-782.

Jacobson L, Akana SF, Cascio CS, Shinsako J, Dallman MF (1988). Circadian variations in plasma corticosterone permit normal termination of the adrenocorticotropin responses to stress. Endocrinology 122: 1343-1348.

Kageyama K, Li C, Vale WW (2003). Corticotropin-releasing factor receptor type 2 messenger ribonucleic acid in rat pituitary: localization and regulation by immune challenge, restraint stress, and glucocorticoids. Endocrinology 144: 1524-2532.

Koob G, Kreek MJ (2007). Stress, dysregulation of drug reward pathways, and the transition to drug dependence. $A m J$ Psychiatry 164: 1149-1159.

Kreek MJ, Koob GF (1998). Drug dependence: stress and dysregulation of brain reward pathways. Drug Alcohol Depend 51: 23-47.

Lê AD, Harding S, Juzytsch W, Watchus J, Shalev U, Shaham Y (2000). The role of corticotrophin-releasing factor in stressinduced relapse to alcohol-seeking behavior in rats. Psychopharmacology 150: 317-324.

Lee B, Tiefenbacher S, Platt DM, Spealman RD (2003). Role of the hypothalamic-pituitary-adrenal axis in reinstatement of cocaineseeking behavior in squirrel monkeys. Psychopharmacology 168: 177-183.

Lee Y, Schulkin J, Davis M (1994). Effect of corticosterone on the enhancement of the acoustic startle reflex by corticotropin releasing factor (CRF). Brain Res 666: 93-98.
Liu J, Yu B, Orozco-Cabal L, Grigoriadis DE, Rivier J, Vale WW et al (2005). Chronic cocaine administration switches corticotropin-releasing factor2 receptor-mediated depression to facilitation of glutamatergic transmission in the lateral septum. J Neurosci 25: 577-583.

Lu L, Liu D, Ceng X (2001). Corticotropin-releasing factor receptor type 1 mediates stress-induced relapse to cocaine-conditioned place preference in rats. Eur J Pharmacol 415: 203-208.

Makino S, Gold PW, Schulkin J (1994a). Effects of corticosterone on CRH mRNA and content in the bed nucleus of the stria terminalis; comparison with the effects in the central nucleus of the amygdala and the paraventricular nucleus of the hypothalamus. Brain Res 657: 141-149.

Makino S, Gold PW, Schulkin J (1994b). Corticosterone effects on corticotropin-releasing hormone mRNA in the central nucleus of the amygdala and the parvocellular region of the paraventricular nucleus of the hypothalamus. Brain Res 640: 105-112.

Makino S, Schulkin J, Smith MA, Pacák K, Palkovits M, Gold PW (1995). Regulation of corticotropin-releasing hormone receptor messenger ribonucleic acid in the rat brain and pituitary by glucocorticoids and stress. Endocrinology 136: 4517-4525.

Mantsch JR, Baker DA, Francis DM, Katz ES, Hoks MA, Serge JP (2008a). Stressor- and corticotropin releasing factor-induced reinstatement and active stress-related behavioral responses are augmented following long-access cocaine self-administration by rats. Psychopharmacology 195: 591-603.

Mantsch JR, Baker DA, Serge JP, Hoks MA, Francis DM, Katz ES (2008b). Surgical adrenalectomy with diurnal corticosterone replacement slows escalation and prevents the augmentation of cocaine-induced reinstatement in rats self-administering cocaine under long-access conditions. Neuropsychopharmacology 33: 814-826.

Mantsch JR, Cullinan WE, Tang LC, Baker DA, Katz ES, Hoks MA et al (2007). Daily cocaine self-administration under long-access conditions augments restraint-induced increases in plasma corticosterone and impairs glucocorticoid receptor-mediated negative feedback in rats. Brain Res 1167: 101-111.

Mantsch JR, Katz ES (2007). Elevated glucocorticoids are necessary but not sufficient for the escalation of cocaine self-administration by chronic electric footshock stress in rats. Neuropsychopharmacology 32: 367-376.

Mantsch JR, Saphier D, Goeders NE (1998). Corticosterone facilitates the acquisition of cocaine self-administration in rats: opposite effects of the type II receptor agonist dexamethasone. J Pharmacol Exp Ther 287: 72-80.

Mantsch JR, Yuferov V, Mathieu-Kia AM, Ho A, Kreek MJ (2003). Neuroendocrine alterations in a rat high-dose, extended-access self-administration model of escalating cocaine use. Psychoneuroendocrinology 28: 836-862.

Mantsch JR, Yuferov V, Mathieu-Kia AM, Ho A, Kreek MJ (2004). Effects of extended access to high versus low cocaine doses on self-administration, cocaine-induced reinstatement and brain mRNA levels in rats. Psychopharmacology 175: 26-36.

Marinelli M, Piazza PV (2002). Interaction between glucocorticoid hormones, stress and psychostimulant drugs. Eur J Neurosci 16: 387-394.

Merali Z, Anisman H, James JS, Kent P, Schulkin J (2008). Effects of corticosterone on corticotrophin-releasing hormone and gastrin-releasing peptide release in response to an aversive stimulus in two regions of the forebrain (central nucleus of the amygdala and prefrontal cortex). Eur J Neurosci 28: 165-172.

Meyer JS, Micco DJ, Stephenson BS, Krey LC, McEwen BS (1979). Subcutaneous implantation method for chronic glucocorticoid replacement therapy. Physiol Behav 22: 867-870.

Morales-Medina JC, Sanchez F, Flores G, Dumont Y, Quirion R (2009). Morphological reorganization after repeated corticosterone administration in the hippocampus, nucleus accumbens and amygdala in the rat. J Chem Neuroanat 38: 266-272. 
Orozco-Cabal L, Liu J, Pollandt S, Schmidt K, Shinnick-Gallagher P, Gallagher JP (2008). Dopamine and corticotropin-releasing factor synergistically alter basolateral amygdala-to-medial prefrontal cortex synaptic transmission: functional switch after chronic cocaine administration. J Neurosci 28: 529-542.

Paxinos G, Watson C (1998). The Rat Brain in Stereotaxic Coordinates, 4th edition. Academic Press: San Diego.

Piazza PV, Le Moal ML (1996). Pathophysiological basis of vulnerability to drug abuse: role of an interaction between stress, glucocorticoids, and dopaminergic neurons. Annu Rev Pharmacol Toxicol 36: 359-378.

Pollandt S, Liu J, Orozco-Cabal L, Grigoriadis DE, Vale WW, Gallagher JP et al (2006). Cocaine withdrawal enhances longterm potentiation induced by corticotropin-releasing factor at central amygdala glutamatergic synapses via CRF, NMDA receptors and PKA. Eur J Neurosci 24: 1733-1743.

Prasad BM, Ulibarri C, Kalivas PW, Sorg BA (1996). Effect of adrenalectomy on the initiation and expression of cocaineinduced sensitization. Psychopharmacology 125: 265-273.

Prasad BM, Ulibarri C, Sorg BA (1998). Stress-induced crosssensitization to cocaine: effect of adrenalectomy and corticosterone after short- and long-term withdrawal. Psychopharmacology 136: 24-33.

Przegaliński E, Filip M, Frankowska M, Zaniewska M, Papla I (2005). Effects of CP 154,536, a CRF1 receptor antagonist, on behavioral responses to cocaine in rats. Neuropeptides 39: 525-533.

Przegaliński E, Filip M, Siwanowicz J, Nowak E (2000). Effect of adrenalectomy and corticosterone on cocaine-induced sensitization in rats. J Physiol Pharmacol 51: 193-204.

Richter RM, Pich EM, Koob GF, Weiss F (1995). Sensitization of cocaine-stimulated increase in extracellular levels of corticotropin-releasing factor from the rat amygdala after repeated administration as determined by intracranial microdialysis. Neurosci Lett 187: 169-172.

Richter RM, Weiss F (1999). In vivo CRF release in rat amygdala is increased during cocaine withdrawal in self-administering rats. Synapse 32: 254-261.

Roozendaal B (2002). Stress and memory: opposing effects of glucocorticoids on memory consolidation and memory retrieval. Neurobiol Learn Mem 78: 578-595.

Rouge-Pont F, Marinelli M, Le Moal M, Simon H, Piazza PV (1995). Stress-induced sensitization and glucocorticoids. II. Sensitization of the increase in extracellular dopamine induced by cocaine depends on stress-induced corticosterone secretion. J Neurosci 15: 7189-7195.

Sandi C (1998). The role and mechanisms of action of glucocorticoid involvement in memory storage. Neural Plast 6: 41-52.

Sarnyai Z, Shaham Y, Heinrichs SC (2001). The role of corticotropin-releasing factor in drug addiction. Pharmacol Rev 53: 209-243.

Schulkin J, Gold PW, McEwen BS (1998). Induction of corticotropin-releasing hormone gene expression by glucocorticoids: implication for understanding the states of fear and anxiety and allostatic load. Psychoneuroendocrinol 23: 219-243.

Shaham Y, Erb S, Leung S, Buczek Y, Stewart J (1998). CP-154,526, a selective, non-peptide antagonist of the corticotropin-releasing factor1 receptor attenuates stress-induced relapse to drug seeking in cocaine- and heroin-trained rats. Psychopharmacology 137: 184-190.

Shaham Y, Funk D, Erb S, Brown TJ, Walker CD, Stewart J (1997). Corticotropin-releasing factor, but not corticosterone, is involved in stress-induced relapse to heroin-seeking in rats. J Neurosci 17: 2605-2614.

Shalev U, Erb S, Shaham Y (2010). Role of CRF and other neuropeptides in stress-induced reinstatement of drug seeking. Brain Res 1314: 15-28.

Shalev U, Finnie PS, Quinn T, Tobin S, Wahi P (2006). A role for corticotropin-releasing factor, but not corticosterone, in acute food-deprivation-induced reinstatement of heroin seeking in rats. Psychopharmacology 187: 376-384.

Shepard JD, Barron KW, Myers DA (2000). Corticosterone delivery to the amygdala increases corticotropin-releasing factor mRNA in the central amygdaloid nucleus and anxiety-like behavior. Brain Res 861: 288-295.

Shepard JD, Schulkin J, Myers DA (2006). Chronically elevated corticosterone in the amygdala increases corticotropin releasing factor mRNA in the dorsolateral bed nucleus of stria terminalis following duress. Behav Brain Res 174: 193-196.

Sinha R, Catapano D, O'Malley S (1999). Stress-induced craving and stress response in cocaine dependent individuals. Psychopharmacology 142: 343-351.

Sinha R, Fuse T, Aubin LR, O’Malley SS (2000). Psychological stress, drug-related cues and cocaine craving. Psychopharmacology 152: 140-148.

Sinha R, Talih M, Malison R, Cooney N, Anderson GM, Kreek MJ (2003). Hypothalamic-pituitary-adrenal axis and sympatho-adrenomedullary responses during stress-induced and drug cue-induced cocaine craving states. Psychopharmacology 170: 62-72.

Specio SE, Wee S, O’Dell LE, Boutrel B, Zorrilla EP, Koob GF (2008). CRF(1) receptor antagonists attenuate escalated cocaine self-administration in rats. Psychopharmacology 196: 473-482.

Wang B, Shaham Y, Zitzman D, Azari S, Wise RA, You ZB (2005). Cocaine experience establishes control of midbrain glutamate and dopamine by corticotropin-releasing factor: a role in stress-induced relapse to drug seeking. J Neurosci 25: 5389-5396.

Wang B, You ZB, Rice KC, Wise RA (2007). Stress-induced relapse to cocaine seeking: roles for the $\operatorname{CRF}(2)$ receptor and CRF-binding protein in the ventral tegmental area of the rat. Psychopharmacology 193: 283-294.

Ward AS, Collins ED, Haney M, Foltin RW, Fischman MW (1999). Blockade of cocaine-induced increases in adrenocorticotrophic hormone and cortisol does not attenuate the subjective effects of smoked cocaine in humans. Behav Pharmacol 10: 523-529.

Wei Q, Lu XY, Liu L, Schafer G, Shieh KR, Burke S et al (2004). Glucocorticoid receptor overexpression in forebrain: a mouse model of increased emotional lability. Proc Natl Acad Sci USA 101: 11851-11856.

Wellman CL (2001). Dendritic reorganization in pyramidal neurons in medial prefrontal cortex after chronic corticosterone administration. J Neurobiol 49: 245-253.

Winhusen T, Somoza E, Harrer JM, Moore E, Ussery T, Kropp F et al (2005). Metyrapone and cocaine: a double-blind, placebocontrolled drug interaction study. Pharmacol Biochem Behav 80: 631-638.

Zhou Y, Spangler R, Ho A, Kreek MJ (2003). Increased CRH mRNA levels in the rat amygdala during short-term withdrawal from chronic 'binge' cocaine. Brain Res Mol Brain Res 114: 73-79.

Zorrilla EP, Valdez GR, Weiss F (2001). Changes in levels of regional CRF-like-immunoreactivity and plasma corticosterone during protracted drug withdrawal in dependent rats. Psychopharmacology 158: 374-381. 